Gut, 1984, 25, 839-845

\title{
Is raised breath hydrogen related to the pathogenesis of pneumatosis coli?
}

\author{
N W READ, M N AL-JANABI, AND P A CANN \\ From the Clinical Research Unit, Royal Hallamshire Hospital, Sheffield, and Department of Physiology, \\ University of Sheffield, Sheffield
}

SUMmARY Clinical and physiological studies were carried out in five patients with pneumatosis coli in order to investigate the origin of the high fasting breath hydrogen concentration in this condition and to determine its possible significance in the pathogenesis of the disease. All five patients excreted abnormally high fasting concentrations of hydrogen in their breath $(69 \pm 9 \mathrm{ppm}$, mean \pm SEM). Moreover, analysis of the contents of the gas filled cysts revealed between $2 \%$ and $8 \%$ of hydrogen gas. Colonic washout significantly reduced breath hydrogen concentrations to $9 \pm 6 \mathrm{ppm}$, but did not abolish the cysts. Conversely, deflation of the cysts was achieved with oxygen or antibiotics, though this only reduced breath hydrogen concentrations to about $66 \%$ of their original value. After feeding a radiolabelled meal, breath hydrogen concentrations rose before the meal appeared to reach the colon, suggesting overgrowth of anaerobic bacteria in the small intestine. Despite this, ${ }^{14} \mathrm{C}$ glycocholate breath tests were within normal limits. An alternative possibility is that the high levels of hydrogen excreted in the breath may be produced in the intestinal lumen possibly from the fermentation of copious amounts of colonic mucus. Finally, measurement of whole gut transit time and stool weight suggested that patients were constipated despite passing mucus and blood. The relevance of our observations to the pathogenesis of submucosal cysts is unclear, but the data favour the hypothesis that these are produced by invasion of the colonic submucosa with anaerobic bacteria.

Pneumatosis coli is an uncommon condition of unknown aetiology, characterised by the presence of multiple gas filled cysts within the wall of the colon. A recent report of raised breath hydrogen concentrations in these patients suggested that increased bacterial fermentation of carbohydrate may be implicated in the pathogenesis of the condition. ${ }^{1} \mathrm{We}$ have carried out a series of studies to investigate the origin of the raised fasting breath hydrogen concentrations in five patients with pneumatosis coli in an attempt to shed some light on the pathogenesis of the condition.

\section{Methods}

PATIENTS

These were three female and two male patients aged between 45 and 60 years who all had submucosal gas filled cysts of the large bowel (Fig. 1), but had no

Address for correspondence: Dr N W Read. Clinical Research Unit. H Floor. Royal Hallamshire Hospital. Glossop Road. Sheffield S10 2JF.

Received for publication: 10 October 1983 evidence of small bowel cysts. For comparison, results were compared with those from 23 normal healthy volunteers ( 11 men and 12 women, aged 21-70 years), who had no bowel complaints, and 29 patients with the irritable bowel syndrome (10 men and 19 women, aged 19-69 years).

\section{Case reports}

CASE NO 1 (AS)

This 69 year old women presented with a two month history of increasing flatulence, associated with passage of blood and mucus per rectum and abdominal pain which was intermittent in nature, and relieved by defaecation. She admitted to constipation and had lost $15.87 \mathrm{~kg}$ in six months. She had suffered with progressive angina for several years and had been treated with oxprenolol $(120 \mathrm{mg}$ tds). She had undergone a cholecystectomy for gall stones eight years previously. There was no history of chronic obstructive airways disease. Rectal biopsy revealed melanosis coli. 


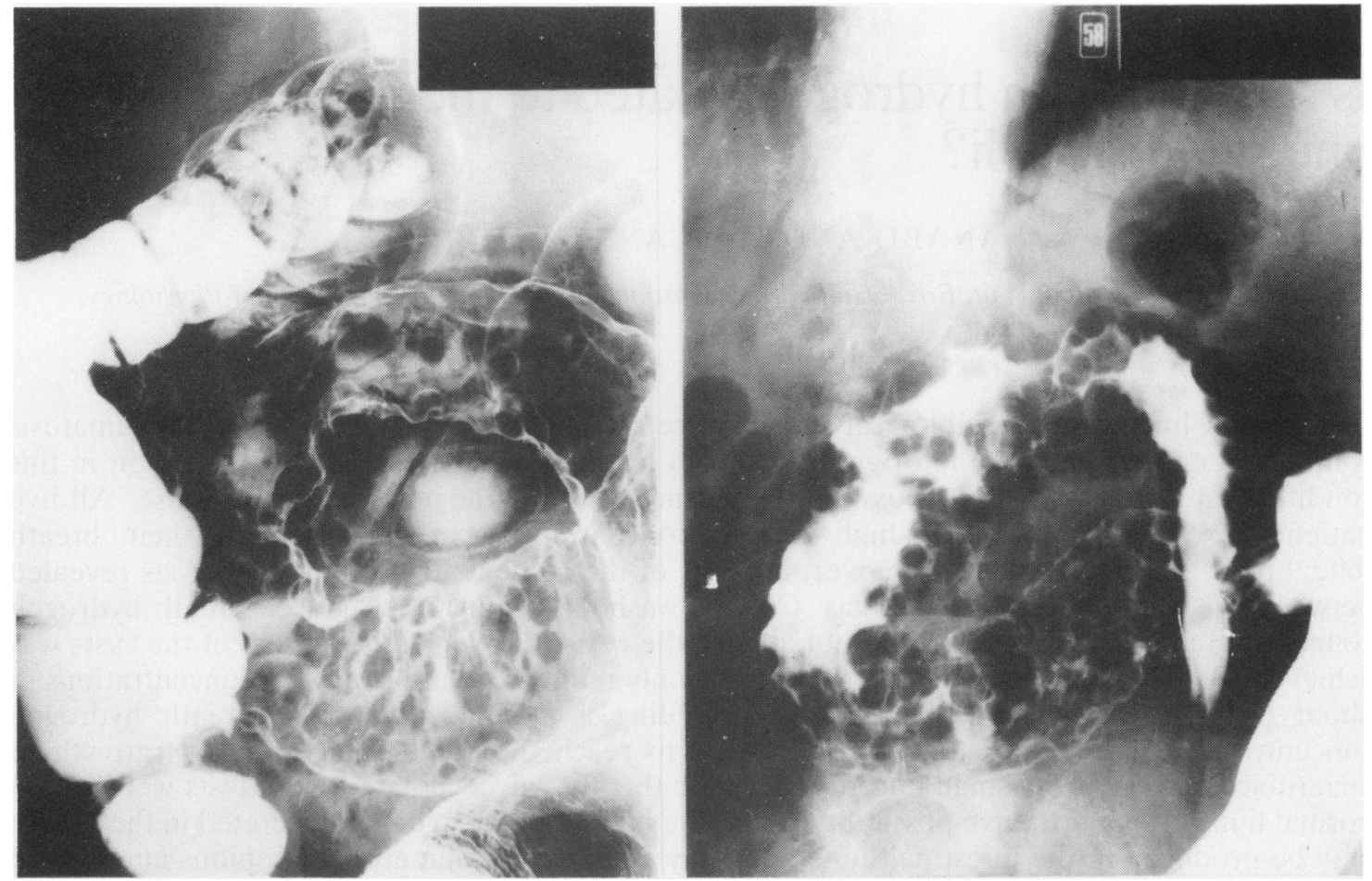

Fig. 1 Double contrast barium enema showing presence of gas filled cysts in a tortuous loop of sigmoid colon.

CASE NO 2 (JR)

This 65 year old retired steelworker presented with symptoms of lower abdominal pain and the passage of blood and mucus per rectum, which began shortly after a transurethral prostatectomy for benign prostatic hyperplasia in 1978 . He admitted to constipation and was taking oxprenolol $(160 \mathrm{mg}$ daily), digoxin $(0 \cdot 25 \mathrm{mg}$ daily), and glyceryl trinitrate tablets for increasing angina of effort and hypertension which he had had for five years. He did not suffer from chronic obstructive airways disease.

CASE NO 3 (AF)

This 59 year old woman had suffered with progressive disseminated sclerosis for three years, which had resulted in a spastic paralysis of both legs and ataxia of the upper limbs. Six months before admission she developed diarrhoea which was watery in consistency and contained no blood or mucus. Bowels were open between four and six times per day, but she did not complain of abdominal pain or the passage of gas per rectum. She gave no history of constipation and denied taking laxatives, though rectal biopsies showed evidence of melanosis coli. She gave no previous history of obstructive airways disease.
CASE NO 4 (cW)

This 61 year old man presented in 1978 with a three week history of passing red blood and mucus per rectum, accompanied by urgency, tenesmus, and passage of copious flatus. There was little abdominal pain and no previous history of constipation. He was taking atenolol (100 $\mathrm{mg}$ daily) and hydralazine (100 $\mathrm{mg}$ bd) for hypertension, and had sustained a myocardial infarction in 1974. His past medical history included polycythaemia, gout, agitated depression, primary hyperparathyroidism, and a bladder tumour. There was no history of chronic obstructive airways disease.

\section{CASE NO 5 ( BC)}

This 45 year old woman presented with a two year history of watery diarrhoea associated with mucus and occasional red blood. The condition had progressively worsened until she was passing motions up to 15 times per day, associated with a copious flatus, but no abdominal pain. There was no history of constipation. She had been treated for one year with amitryptilene ( $25 \mathrm{mg}$ bd) and carbamezepine (200 mg tds) for frontal headaches associated with vomiting. There was no previous history of obstructive airways disease or ischaemic heart disease. 
INVESTIGATIVE PROTOCOL

All patients underwent extensive clinical investigations as outpatients. The following tests were carried out in all patients: full blood count; blood urea and electrolytes; liver function tests; Serum $\mathrm{B}_{12}$ and folate; ${ }^{14} \mathrm{C}$ glycocholate breath test, ${ }^{2}$ barium meal and follow through, barium enema, plain abdominal radiograph, and sigmoidoscopy. In addition, jejunal biopsy and colonoscopy were carried out in three patients.

Patients were admitted to our gastrointestinal ward for at least a week so that the special tests could be carried out in the following order: fasting breath hydrogen analysis, measurement of gastrointestinal transit times (three days), further fasting breath hydrogen analysis ( 24 hour fast), colonic irrigation, analysis of contents of submucosal cysts, response to treatment. Patient 5 was unwilling to delay treatment and only underwent fasting breath hydrogen analysis and colonic irrigation before treatment.

BREATH HYDROGEN CONCENTRATIONS

Samples of end expiratory air $(50 \mathrm{ml})$ were collected after fasts of at least 14 hours, and 24 hours (four patients), after colonic irrigation using mannitol by mouth and rectal enemas, and after therapy with oxygen and antibiotics. Samples were taken in triplicate and the concentration of hydrogen in these samples was determined by means of a detector which incorporated a metallised membrane gas sensitive electrode (GMI, Renfrew; Hansatech, Kings Lynn). ${ }^{3+}$

\section{MEASUREMENT OF INTESTINAL. TRANSIT TIMES}

The time taken for food to pass through the samll intestine and colon was investigated by feeding a standard meal, containing mashed potato, baked beans, sausages, and a dessert consisting of homogenised pineapple in custard. The mashed potato was labelled with $500 \mu \mathrm{Cie}{ }^{99 \mathrm{~m}}$ Technetium sulphur colloid and 50 radio-opaque plastic markers. ${ }^{5}$ Small bowel transit time of the radiolabelled test meal and the rate of colonic filling was estimated by breath hydrogen analysis ${ }^{4} 5$ and by a system incorporating a gamma camera and dedicated minicomputer. ${ }^{6}$ Previous studies carried out in patients with terminal ileostomies had shown that radioactive technetium ${ }^{99}$ incorporated in mashed potato provides an accurate marker for the delivery of both liquid and solid residues from a similar solid test meal through the terminal ileum. ${ }^{7}$

Whole gut transit time was determined by asking patients to collect the contents of each individual bowel movement in plastic bags for three days after ingestion of the standard meal. These were inspected, weighed, and radiographed to determine the number of radio-opaque plastic markers passed within 72 hours of ingestion of the meal. ${ }^{58}$

ANALYSIS OF CONTENTS OF SUBMUCOSAL CYSTS This was carried out in three patients who had cysts in the high rectum or low sigmoid colon. After colonic washout, the rectum and sigmoid colon were examined with the flexible sigmoidoscope. The surface of a cyst was washed by irrigation with a fine catheter inserted through the biopsy channel and then punctured with the end of a 21 gauge needle attached to another catheter and inserted through the biopsy channel of the instrument. The gas in the cyst was aspirated using a $5 \mathrm{ml}$ syringe. The contents of several cysts were sampled in this way. The concentration of hydrogen in these samples was estimated by the detector after suitable dilutions.

\section{TREATMENT PROTOCOLS}

All patients were eventually treated with $100 \%$ oxygen, ${ }^{911}$ delivered via a face mask for periods of between four and seven days. On this regime the $\mathrm{PaO}_{2}$ varied from 23.7 to $35 \cdot 2 \mathrm{kPa}$ (normal= 13.2 $\mathrm{kPa})$.

In two patients, treatment of the condition was initially attempted with courses of antibiotics (either metronidazole $200 \mathrm{mg}$ tds, or oxytetracycline $250 \mathrm{mg}$ qds, or trimethoprimsulfamethoxazole 2 tabs bd, or erythromycin $250 \mathrm{mg}$ qds for a total period of three months).

\section{STATISTICAL METHODS}

The statistical significance of differences between the data was analysed using Student's paired or unpaired $t$ test, whichever was appropriate.

\section{Results}

\section{CLINICAL INVESTIGATIONS}

Radiological and endoscopic investigation revealed evidence of gas filled submucosal cysts in the colon of all five subjects (Fig. 1). The extent of the disease varied from the whole colon (cases 3 and 4 ) to the descending colon, sigmoid colon, and rectum (cases 1,2 , and 5). In each case the presence of cysts was associated with large amounts of faecal residue in the proximal colon.

In contrast, radiological examination did not reveal gas filled cysts in the small intestine, nor did they show any evidence of any other small intestinal disease. None of the biochemical or haematological tests indicated any evidence of malabsorption. Moreover, the results of the ${ }^{14}$ glycocholate breath tests were within normal limits and did not suggest bacterial overgrowth of the small intestine. 
BREATH HYDROGEN ANALYSIS

All patients excreted high concentrations of hydrogen in their breath after fasting overnight and after fasting for 24 hours (Table 1). These were significantly higher than those observed in normal subjects or in patients presenting with idiopathic constipation or diarrhoea. After colonic wash out with enemas and mannitol by mouth for three days, breath hydrogen concentrations fell to less than 10 ppm in all except one subject $(\mathrm{p}<0 \cdot 01)$, even though this treatment did not cause any apparent reduction in the number and size of the cysts. Treatment of two patients with metronidazole for two weeks caused a small reduction in breath hydrogen concentration to values that were still abnormally high and caused temporary disappearance of the cysts in one patient. Oxygen treatment abolished the cysts (Fig. 2) and the patients' symptoms, but even after this treatment, breath hydrogen concentrations were only reduced from an average of 69 to $42 \mathrm{ppm}$.

SMALL BOWEL TRANSIT TIME

Breath hydrogen concentrations increased within 100 minutes of ingesting a solid meal in all patients tested (Table 2). In contrast, analysis of the gamma
Table 1 Breath hydrogen concentrations (ppm) in five patients with pneumatosis coli compared with values obtained in normal subjects of patients with diarrhoea or constipation

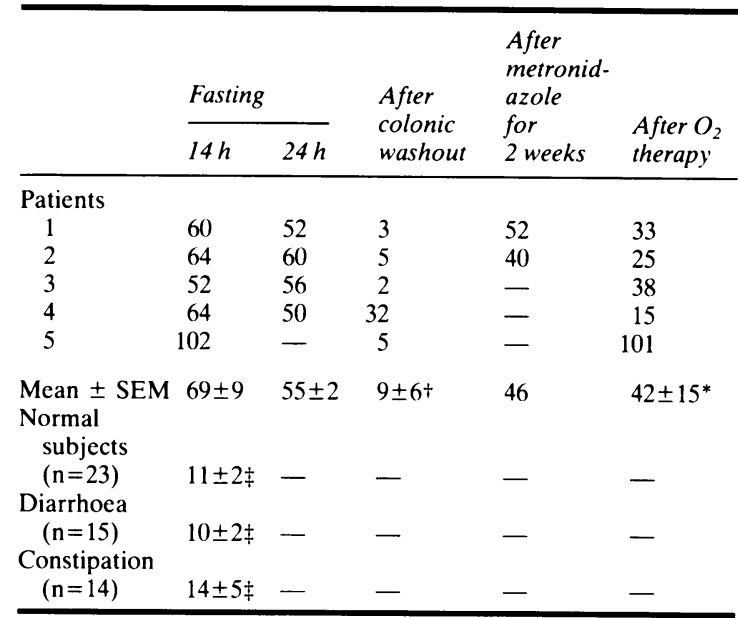

Results from different groups are expressed as mean \pm SEM. Degree of significance of the difference between the value indicated and $14 \mathrm{~h}$ fasting hydrogen levels from patients with pneumatosis coli: ${ }^{*} p<0 \cdot 05,+p<0 \cdot 01, \ddagger p<0 \cdot 001$.
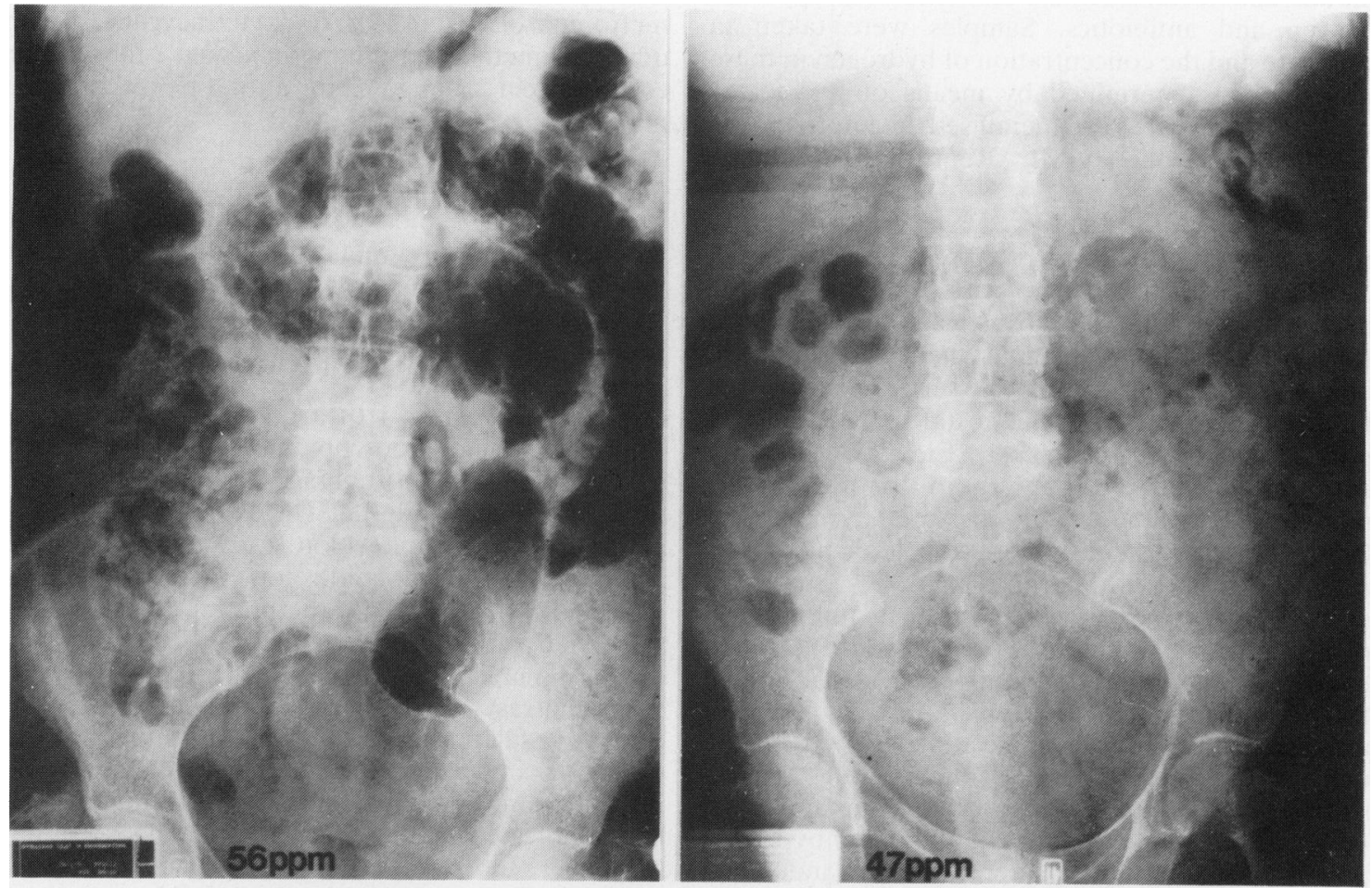

Fig. 2 Plain radiograph of the abdomen in patient with pneumatosis coli before (left) and after (right) treatment with oxygen. Fasting breath hydrogen concentrations, measured at time film was taken, are inserted underneath each film. 
Table 2 Measurements of stool weight, rise in breath hydrogen concentration, and transit time of food through the small and large intestine in four patients with pneumatosis coli and the average results from 23 normal subjects

\begin{tabular}{|c|c|c|c|c|}
\hline & $\begin{array}{l}\text { Rise in } \\
\text { breath } \mathrm{H}_{2} \\
\text { concen- } \\
\text { tration } \\
\text { (min) }\end{array}$ & $\begin{array}{l}\text { Onset } \\
\text { caecal } \\
\text { filling } \\
(\text { min })\end{array}$ & $\begin{array}{l}\text { Daily } \\
\text { stool } \\
\text { weight } \\
\text { (g) }\end{array}$ & $\begin{array}{l}\text { Percentage } \\
\text { of markers } \\
\text { delivered } \\
\text { in } 72 h\end{array}$ \\
\hline \multicolumn{5}{|l|}{ Patients } \\
\hline 1 & 25 & 325 & 70 & 0 \\
\hline 2 & 60) & 1601 & () & 0 \\
\hline 3 & 30) & 345 & 50 & 0 \\
\hline 4 & 20 & 295 & 0 & () \\
\hline $\begin{array}{l}\text { Normal (23) } \\
\quad(\text { mean } \pm \text { SEM })\end{array}$ & $248 \pm 10$ & $176 \pm 26$ & $1.32 \pm 15$ & $83 \pm 3$ \\
\hline
\end{tabular}

camera images indicated that in all patients tested the radioactive marker in the food did not enter the colon until several hours later (Fig. 3).

STOOL WEIGHT AND WHOI.E GUT TRANSIT TIME

Two patients did not pass any motion during the period of collection, two more passed $50 \mathrm{~g}$ and $70 \mathrm{~g}$ of material which consisted largely of mucus. None of the patients passed any radio-opaque markers for three days after ingesting the meal.

ANALYSIS OF THE CYST CONTENTS

This was carried out in three patients (2. 3. and 4). In all instances, the cysts contained relatively high concentrations of hydrogen gas $\left(2{ }^{2} r .4 \%\right.$, and $7 \cdot 4 \%$ : 20000,40000 , and $74000 \mathrm{ppm}$ respectively).

RESPONSES TO THERAPY

Case 1 was initially treated with courses of metronidazole, oxytetracycline, and erythromycin. These failed to relieve her symptoms or reduce the size of a number of cysts. The cysts responded to four days of oxygen therapy, however. and have not recurred for over two years. Although her symptoms improved after oxygen treatment. she still remains constipated with intermittent abdominal pain and requires regular treatment with laxatives.

Case 2 was initially treated with metronidazole. On this regime, the cysts disappeared and his symptoms improved. Within three weeks his symptoms had returned and the cysts had reformed. Long term treatment with metronidazole for three months was ineffective, as were courses of oxytetracycline and trimethoprim-sulfamethoxazole. After three days' treatment with oxygen the patient had improved clinically and a plain radiograph of the abdomen showed no further evidence of cysts in the large bowel. He has been followed for two years, during which he suffered no relapse, either clinically or radiologically.

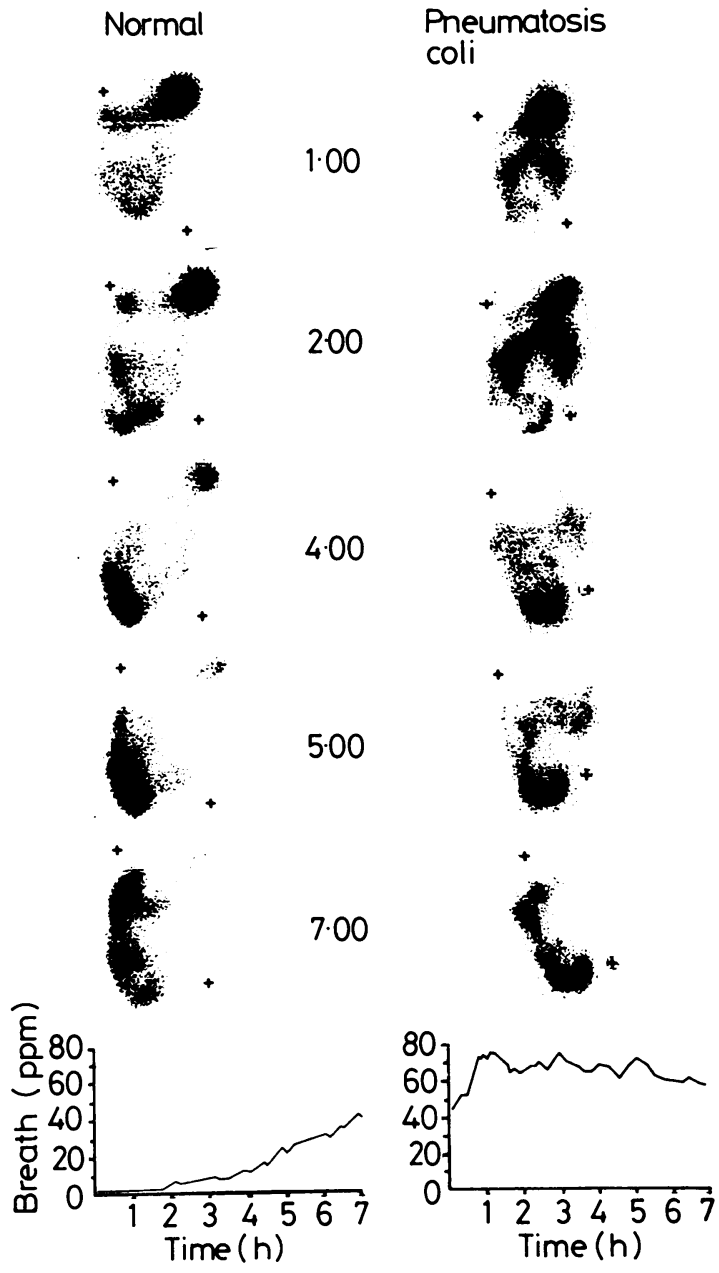

Fig. 3 Breath hydrogen profiles and images of distribution of radioactivity in abdomen at successive intervals (hours and minutes) after ingesting a solid meal in a typical patient with pneumatosis coli (right) and typical normal subject (left). Note that in normal subject, radiolabelled meal appeared to enter caecum from ileum approximately two hours after ingesting meal. This was accompanied by a rise in breath hydrogen excretion. In patient with pneumatosis coli, radiolabelled meal did not appear to enter the caecum until five hours and 30 minutes after ingestion, whereas an increase in breath hydrogen excretion had occurred within an hour of eating the meal. Crosses on each image indicate the position of markers on end of left ninth rib in midclavicular line and left anterior superior iliac spine.

Cases 3 and 5 were successfully treated with oxygen and have had no recurrence of their colonic cysts or symptoms over a follow up period of at least a year.

Case 4 was also successfully treated with oxygen. 
He remained free of abdominal symptoms until 1981, when his condition recurred, but again responded to treatment with oxygen. He has suffered a further relapse, requiring oxygen, this year.

\section{Discussion}

Hydrogen gas cannot be produced by the metabolism of mammalian cells and can only be formed in the body by bacterial fermentation of carbohydrate. As such, hydrogen is usually formed in normal subjects when the unabsorbed carbohydrate in the diet enters the colon and is fermented by colonic micro-organisms. ${ }^{5} 11$ The persistently raised concentrations of hydrogen excreted in the breath of patients with pneumatosis coli implies that a population of enteric bacteria is encountering an abundant source of carbohydrate, even many hours after eating a meal. One possibility is that the majority of hydrogen is formed in the cysts themselves by fermentation of plasma glucose. In support of this is the observation that high concentrations of $\mathrm{H}_{2}$ can be found within the cysts; ${ }^{9}{ }^{12}{ }^{1.3}$ a result that we have confirmed in these studies. Against it is the finding that the breath hydrogen excretion can be reduced to basal values by colonic irrigation without affecting the size or the number of the cysts, and the observation that after abolition of the cysts by antibiotics or oxygen, the breath hydrogen excretion was still abnormally high. These results strongly suggest that the abnormally high hydrogen production is coming from the bowel lumen itself. Among the possibilities which could explain this phenomenon are chronic ingestion of large quantities of unabsorbable carbohydrate, carbohydrate malabsorption, overgrowth of the small intestine with gas forming bacteria, or the fermentation of a copious secretion of mucus in the large intestine. ${ }^{14} \mathrm{~A}$ careful dietary history showed that the patients were not ingesting large amounts of unabsorbable carbohydrate in their normal diet. Moreover, all of our patients were well nourished and had no clinical evidence of malabsorption, though we did not carry out formal tests of pancreatic function or lactose tolerance in any of them.

Measurement of breath hydrogen after ingesting a meal indicated that the hydrogen concentrations rose at a time when the radioactive markers in the meal had not reached the colon. As there is a normally close correlation between the rise in hydrogen and the entry of a radiolabelled meal into the colon,$^{56}$ and since the radioactive marker is in the liquid phase of the meal, this discrepancy is unlikely to be due to an unusually early arrival of the liquid phase of the meal at the caecum. It is also unlikely to be caused by fermentation by bacteria in the mouth ${ }^{15}$ as the rises in breath hydrogen concentration observed in samples of end respiratory air from our patients are much higher and occur later and have a longer duration than the transient rises reported for buccal fermentation of a bean meal in normal subjects. ${ }^{15}$ Instead the result suggests that carbohydrate may have been encountering gas forming bacteria in the small intestine before the meal had reached the colon. In support of this interpretation is the observation that the radiolabelled meal reached the colon very slowly in three of our patients. Against it is the observation that the ${ }^{14} \mathrm{C}$ glycocholate test did not confirm bacterial overgrowth in any of our patients, though false negative results for this test are not uncommon, ${ }^{16}$ and the observation that high breath hydrogen concentrations were recorded even in patients that had been fasted for over 24 hours. A further possibility is that the raised fasting hydrogen levels were generated by fermentation of the large amounts of colonic mucus, ${ }^{14}$ which may in turn be stimulated after meal ingestion. Our data do not permit us to convincingly decide which, if either, of these two possibilities accounts for the high fasting breath hydrogen concentrations.

Although patients with pneumatosis coli pass large quantities of blood stained mucus, they pass little stool and measurement of colonic transit times indicate that they are very constipated. This may be explained in part by obstruction of the passage of stools by the cysts, though two of our patients remained constipated even after the cysts had disappeared.

Whether excessive hydrogen production in the intestinal lumen plays any role in the production of the gas filled cysts is unclear from our data. Several different theories exist to explain the origin of the cysts. Previous experimental studies have shown that it is possible for air which has leaked into the mediastinum through a ruptured emphysematous bulla - for example, to track down and produce gas bubbles in the subserosa of the intestine. ${ }^{17}$ It is less easy to envisage how this mechanism could result in submucosal cysts, just confined to the colon. Moreover, none of the patients that we studied had chronic obstructive airways disease. A second theory proposes that gas, produced in the intestinal lumen, could enter the submucosa through breaches in the epithelium. This explanation has been invoked to explain cysts found in association with duodenal ulceration, ${ }^{18}$ at surgical anastomoses, ${ }^{19}$ and after sigmoidoscopy. ${ }^{20}$ We did not observe any obvious breach of the colonic mucosa at colonoscopy in any of our patients, and none had 
undergone a sigmoidoscopy before the onset of their disease. Moreover, if gas were entering from the lumen continuously via a mucosal breach, it is unlikely that the cysts would disappear on oxygen therapy or antibiotics when clearly this therapy does not prevent gas formation within the colonic lumen, and it is equally unlikely that cysts would remain when the colonic contents were flushed out.

In our opinion, the most likely explanation for the origin of the cysts is the invasion of the colonic wall by gas forming anaerobic bacteria. In support of this, pneumatosis coli has been produced experimentally by injecting bacteria under the intestinal mucosa. ${ }^{21} 22$ If this is true, increasing the $\mathrm{PO}_{2}$ or giving antibiotics would prevent cyst formation by creating an unfavourable environment for the anaerobic bacteria within the bowel wall, although this treatment would be unlikely to influence markedly the anaerobic populations and gas production in the colonic mass of faeces. On the other hand, it is necessary to postulate a low oxygen tension within the bowel wall for survival of anaerobic bacteria in the colonic submucosa of patients with pneumatosis coli. This could occur in respiratory failure or in colonic ischaemia, and may explain the observed relationships between pneumatosis coli and cystic fibrosis, ${ }^{23}$ obstructive airways disease, ${ }^{164}$ or arteriosclerosis. ${ }^{1}$ In this regard, it is notable that three patients we studied were arteriopathic.

In conclusion, our data suggest that the high fasting breath hydrogen concentrations found in patients with pneumatosis coli may be produced in the intestinal lumen, either by the fermentation of copious amounts of mucus in the colon, or by fermentation of dietary carbohydrate by bacteria in the small intestine. We have been unable to discern any clear relationship between the raised breath hydrogen concentrations and the formation of cysts.

\section{References}

1 Gillon J, Tadesse K, Logan RFA. Holt S. Sircus W. Breath hydrogen in pneumatosis cystoides intestinalis. Gut 1979; 20: 1008-11.

2 Scarpello JHB, Sladen GE. Appraisal of the ${ }^{1+C}$ glycocholate acid test with special reference to the measurement of faecal ${ }^{14} \mathrm{C}$ excretion. Gut 1977: 18: $742-8$.

3 Bergman I, Coleman JE, Evans D. A simple gas chromatograph with an electrochemical detector for the measurement of hydrogen and carbon monoxide in the parts per million range, applied to exhaled air. Chromatographia 1975; 8: 581-3.

4 Corbett CL, Thomas S, Read NW. Hobson N. Bergman I. Holdsworth CD. Electrochemical detector for breath hydrogen determination: measurement of small bowel transit time in normal subjects and patients with the irritable bowel syndrome. Giut 1981; 22: 836-40.

5 Read NW, Miles CA, Fisher D et al. Transit of a meal through the stomach, small intestine and colon in normal subjects and its role in the pathogenesis of diarrhoea. Gastroenterology 1980; 79: 1276-82.

6 Read NW, Al-Janabi MN, Bates TE, Barber DC. Effect of gastrointestinal intubation on the passage of a solid meal through the stomach and small intestine in humans. Gastroenterology 1983; 84: 1568-72.

7 Holgate AM, Read NW. Can a rapid small bowel transit limit absorption. [Abstract] Gut 1982; 23: A 192.

8 Hinton JM, Lennard Jones JE. Young AC. A new method for studying gut transit times using radioopaque markers. Gut 1979; 20: 842-7.

9 Forgacs P, Wright PH, Wyatt AP. Treatment of intestinal gas cysts by oxygen breathing. Lancet 1973; 1: 579-81.

10 Down RHL, Castleden WM. Oxygen therapy for pneumatosis coli. Br Med J 1975; 1: 493-4.

11 Bond $\mathrm{JH}$, Levitt MD. Investigation of small bowel transit in man, utilizing pulmonary hydrogen $\left(\mathrm{H}_{2}\right)$ measurements. J Lab Clin Med 1974; 85: 546-59.

12 Hughes DTD, Gordon KCD, Swann JC, Bolt GL. Pneumatosis cystoides intestinalis. Gut 1966; 7: 553-7.

13 Hoflin F, van der Linden W. Pneumatosis cystoides intestinalis treated by oxygen breathing. Scand $J$ Gastroenterol 1974; 9: 427-30.

14 Perman JA, Modler S. Glycoproteins as substrates for production of hydrogen in the large intestine. Gastroenterology 1982; 83: 388-93.

15 Thompson DG, O'Brien J, McCarthy M, Hardie J. Oral microflora affect postprandial exhaled breath hydrogen concentrations. [Abstract] Gut 1983; 24: A978.

16 Caspary WF. Breath tests. Clinics in gastroenterology 1978; 7: 351-74.

17 Keyting WS, McCarver RR, Kovrik JL, Daywitt AL. Pneumatosis intestinalis: a new concept. Radiology 1961; 76: 733-41.

18 Koss LG. Abdominal gas cysts (pneumatosis cystoides intestinum hominis). Arch Pathol 1952; 53: 537-47.

19 Sicard GA, Vaughan R, Wise L. Pneumatosis cystoides intestinalis: an unusual complication of jejuno-ileal bypass. Surgery 1976; 79: 480-4.

20 Marshak RH, Blum SD, Eliasoph J. Pneumatosis involving the left side of the colon. JAMA 1956; 161: 1626-8.

21 Stone HH, Allen WB, Smith BB III, Haynes CD. Infantile pneumatosis intestinalis. J Surg Res 1968; 8: 301-6.

22 Yale CE, Batish E, Wu JR. The bacterial etiology of pneumatosis cystoides intestinalis. Arch Surg 1974; 109: 89-94.

23 Wood RE, Herman CJ, Johnson KW. Di Sant'Agnese PA. Pneumatosis coli in cystic fibrosis. Am J Dis Child 1975; 29: 246-8.

24 Elliott GB, Elliott KA. The roentgenologic pathology of so-called pneumatosis cystoides intestinalis. AJR 1963; 89: 720-9. 